\title{
Association of Blood Subgroups With PCR Test Positivity and Lung Involvement in Patients With COVID-19
}

\author{
Yonca Coluk ${ }^{1}$, Omer Hizli ${ }^{2}$, Selda Gunaydın ${ }^{3}$, Guven Yildirim ${ }^{1}$, Elif Baysal ${ }^{1}$, Guliz Ozgen Hergul ${ }^{4}$ \\ 1. Department of Otolaryngology, Giresun University, Faculty of Medicine, Giresun, TUR 2. Department of \\ Otolaryngology, Balikesir University, Faculty of Medicine, Balikesir, TUR 3. Department of Pulmonary Medicine, \\ Giresun University, Giresun, TUR 4. Department of Psychiatry, Giresun University, Faculty of Medicine, Giresun, TUR
}

Corresponding author: Omer Hizli, hizliomer@gmail.com

\section{Abstract}

\section{Objective}

The goal of this study was to investigate whether blood group type caused susceptibility to COVID-19 infection.

\section{Methods}

Two hundred and eleven consecutive patients admitted with various symptoms associated with COVID-19 were included. We compared the $\mathrm{AB} 0$ and Rh subgroup distributions between patients with a positive polymerase chain reaction (PCR) test result and the patients without. We compared the AB0 and Rh subgroup distributions between patients with lung involvement and patients without. Additionally, comparisons were performed between the patients both with positive PCR result and lung involvement, and the patients with a negative PCR result.

\section{Results}

No significant difference of $\mathrm{ABO}$ and $\mathrm{Rh}$ subgroup distributions was evident between patients with and without a positive $\mathrm{PCR}$ test result $(\mathrm{p}=0.632$ and $\mathrm{p}=0.962$ ). No significant difference of $\mathrm{ABO}$ and $\mathrm{Rh}$ subgroup distributions was evident between the patients with and without lung involvement ( $\mathrm{p}=0.097$ and $\mathrm{p}=0.797$ ). No significant difference of $\mathrm{ABO}$ and Rh subgroup distributions was evident among patients both with PCR positivity and lung involvement, patients with only PCR positivity, and the patients with negative PCR test results ( $\mathrm{p}=0.3$ and $\mathrm{p}=0.993)$.

\section{Conclusion}

All blood group types seem to have an equal risk of COVID-19 infection. Everyone should follow the precautions to avoid the COVID-19 infection.

Review began 03/17/2021 Review ended 03/26/2021 Published 03/29/2021

๑) Copyright 2021

Coluk et al. This is an open access article distributed under the terms of the Creative Commons Attribution License CC-BY 4.0., which permits unrestricted use, distribution, and reproduction in any medium, provided the original author and source are credited.
Categories: Internal Medicine, Otolaryngology, Infectious Disease

Keywords: blood groups, covid-19, sars-cov-2, lung involvement

\section{Introduction}

Coronaviruses are a large family of viruses causing mild, self-limiting infections common in the general population, like common cold, also more serious infections such as middle east respiratory syndrome (MERS) and severe acute respiratory syndrome (SARS) [1]. The coronavirus disease-2019 (COVID-19) caused by SARS-CoV-2 subtype of coronavirus was declared as a pandemic in March 2020 by World Health Organization [2].

Risk factors that may create susceptibility to COVID-19 were investigated in various studies. Comorbidities such as respiratory and cardiovascular disease, advanced age and male gender are known to be the main risk factors increasing the susceptibility to Covid-19 and the severity of the disease [3]. The effects of ABO and Rh blood subgroup differences on the characteristic of the disease in patients with COVID-19 are still a matter of debate. In the prior literature, there exist a limited number of studies investigating the association of COVID-19 with blood groups [4-7].

The goal of this retrospective, cross-sectional study was to investigate the blood group distribution of COVID-19 patients and to determine whether any blood group type caused a susceptibility to this viral infection.

\section{Materials And Methods}




\section{Cureus}

\section{Patients, groups, and study design}

This study was conducted in accordance with the dictates of World Health Organization- Declaration of Helsinki, after providing the official permission of Turkish Ministry of Health, Scientific Research Committee for COVID-19, with the informed consent of the patients and approval of the local ethical committee (IRB Number: 22.05.2020/17). Two hundred and eleven consecutive patients admitted to the outpatient clinic of COVID-19 with various symptoms that might be associated with COVID-19 were included in the study. Medical information of all patients including age, gender, PCR test results, lung involvement status (detected by thorax $\mathrm{CT}$ ), $\mathrm{ABO}$ and $\mathrm{Rh}$ blood subgroups were recorded retrospectively. Excluded from the study were only the patients under the age of 18 years.

Thorax CT investigations were performed using a 16-slice CT unit (Somatom Emotion; Siemens, Munich, Germany) with Picture Archiving Communication Systems (PACS) (Akgun, Ankara, Turkey). The patients with any specific CT finding of COVID-19 were considered as having a lung involvement. The PCR tests for detecting COVID-19 were performed using Biospeedy ${ }^{\circledR}$ COVID-19 qPCR Detection Kit (Bioeksen R\&D Technologies Ltd., Istanbul, Turkey). We constituted a variety of study groups for the comparison of ABO blood subgroups and Rh subgroups of the patients with COVID-19, to determine whether an association of blood subgroups was present with PCR positivity and lung involvement. First, we compared the ABO and Rh subgroup distributions between the patients with a positive PCR test result and the patients without (Figures $1,2)$.

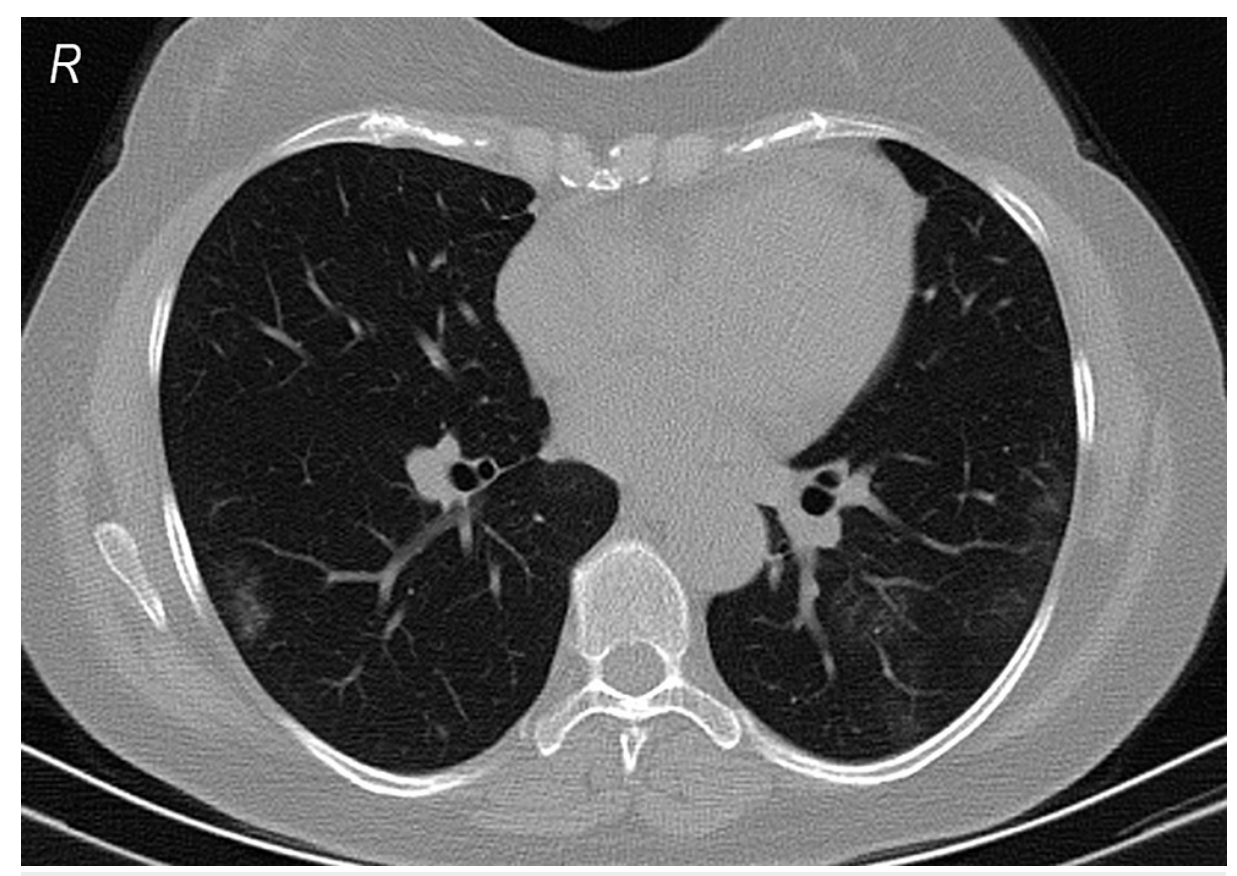

FIGURE 1: Lung involvement in a 46-year-old woman with a positive PCR test result.

PCR: polymerase chain reaction. 


\section{Cureus}

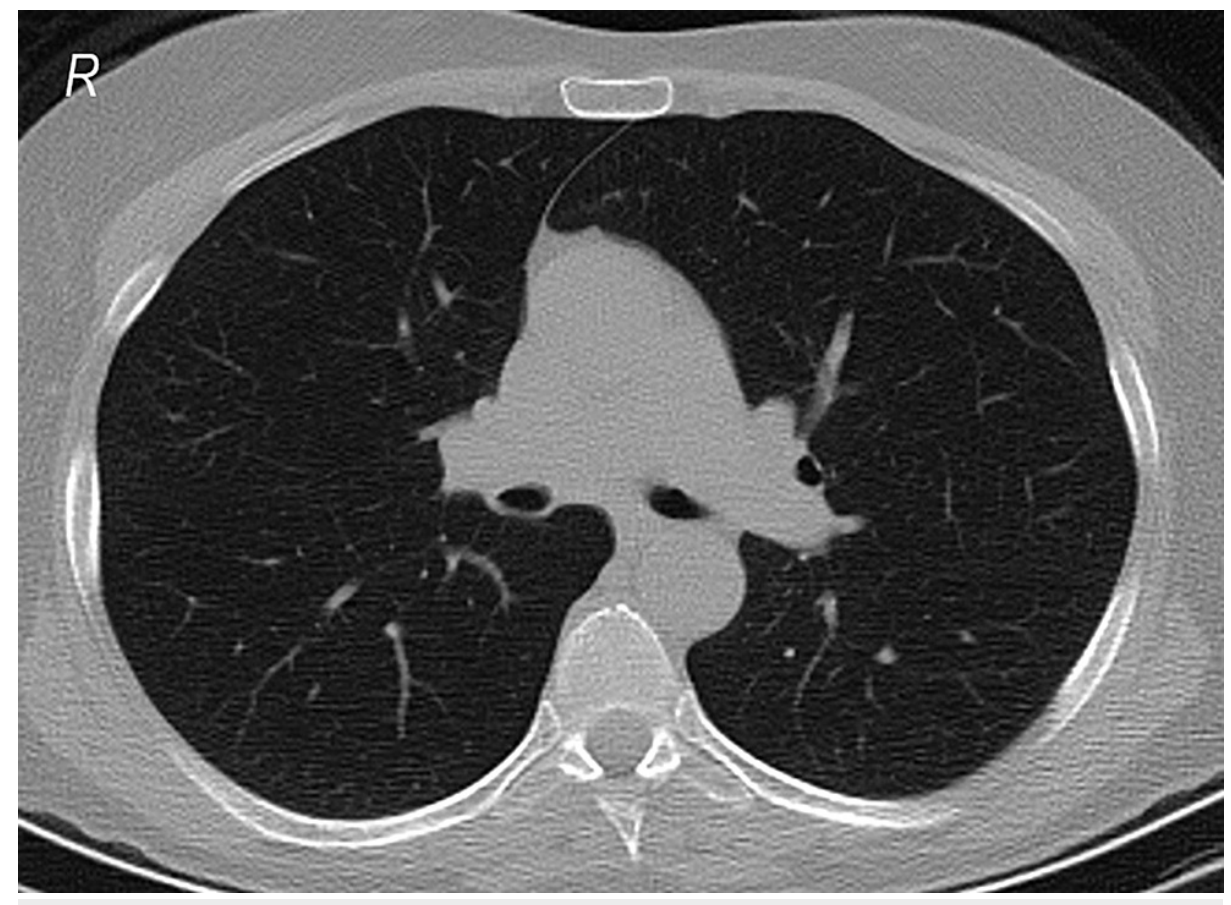

FIGURE 2: A CT radiograph of a 61-year-old woman without CT findings and with a positive PCR test result.

PCR: polymerase chain reaction.

Then, we compared the $\mathrm{ABO}$ and Rh subgroup distributions between the patients with lung involvement and the patients without (Figure 3). Last, the comparisons were performed between the patients both with positive PCR result and lung involvement, and the patients with a negative PCR result. 


\section{Cureus}

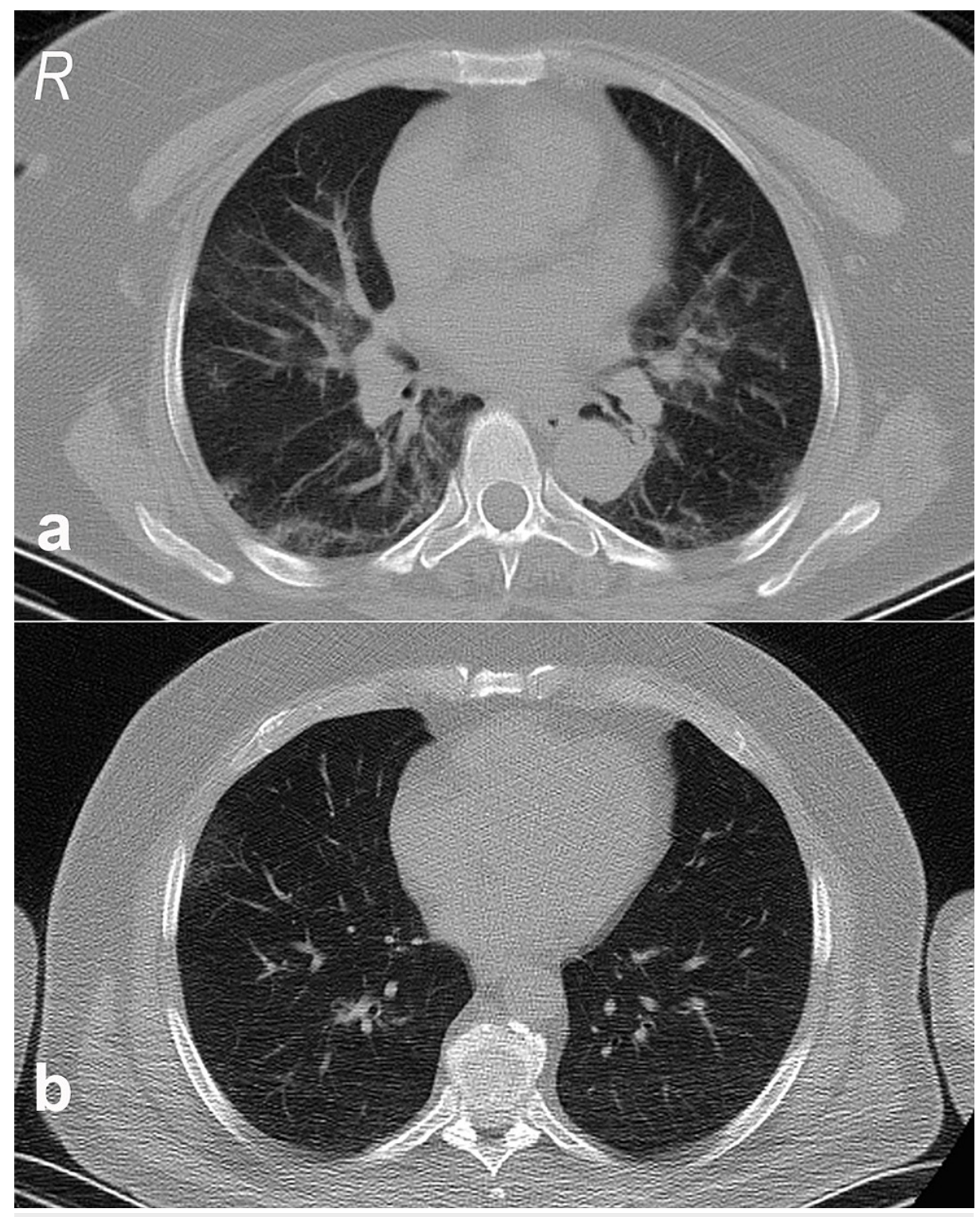

FIGURE 3: (a) Specific thorax CT findings of a 63-year-old woman with a negative PCR test result. (b) Specific thorax CT findings of a 57-year-old man with a positive PCR test result.

PCR: polymerase chain reaction.

\section{Statistical analysis}

Results were presented as number (percentage). For the comparisons of the blood subgroup distributions, Chi- square test was used. The cross-tab analysis results were presented in tables. Statistical analysis was performed using SPSS 23.0 software for Windows (SPSS Inc., Chicago, IL). A p-value under 0.05 was considered statistically significant.

\section{Results}

Among 211 patients totally included, 144 (68.25\%) had a positive PCR test result and 67 (38.75\%) had a negative PCR test result. While 154 (73\%) patients had a lung involvement, 57 (27\%) patients had no finding in thorax CT sections. The number of the patients both with positive PCR result and lung involvement was 97 (46\%).

Table 1 presents the $\mathrm{ABO}$ subgroup distributions, and Table 2 presents the $\mathrm{Rh}$ subgroup distributions of the patients with and without PCR positivity. Chi- square analysis revealed that no significant difference of $\mathrm{ABO}$ and Rh subgroup distributions was evident between the patients with and without a positive PCR test result $(\mathrm{p}=0.632$ and $\mathrm{p}=0.962$, respectively). 


\section{Cureus}

\begin{tabular}{|c|c|c|c|c|c|c|}
\hline & & \multicolumn{4}{|c|}{ ABO blood subgroup } & \multirow{2}{*}{ Total } \\
\hline & & A & B & 0 & $A B$ & \\
\hline \multirow{2}{*}{ PCR } & Negative & 32 (47.7\%) & 12 (17.9\%) & $19(28.4 \%)$ & $4(6 \%)$ & $67(100 \%)$ \\
\hline & Positive & 69 (47.9\%) & 20 (13.9\%) & 50 (34.7\%) & $5(3.5 \%)$ & 144 (100\%) \\
\hline Total & & $101(47.9 \%)$ & $32(15.2 \%)$ & $69(32.7 \%)$ & $9(4.2 \%)$ & 211 (100\%) \\
\hline
\end{tabular}

TABLE 1: Comparison of ABO subgroup distributions of the patients with and without PCR positivity.

$p=0.632$. PCR: polymerase chain reaction.

\begin{tabular}{|c|c|c|c|c|}
\hline & & \multicolumn{2}{|c|}{ Rh blood subgroup } & \multirow{2}{*}{ Total } \\
\hline & & Negative & Positive & \\
\hline \multirow{2}{*}{ PCR } & Negative & 9 (13.4\%) & 58 (86.6\%) & 67 (100\%) \\
\hline & Positive & 19 (13.2\%) & 125 (86.8\%) & 144 (100\%) \\
\hline Total & & 28 (13.3\%) & 183 (86.7\%) & 211 (100\%) \\
\hline
\end{tabular}

TABLE 2: Comparison of Rh subgroup distributions of the patients with and without PCR positivity.

$\mathrm{p}=0.962$. PCR: polymerase chain reaction.

Table 3 presents the ABO subgroup distributions, and Table 4 presents the Rh subgroup distributions of the patients with and without lung involvement. Chi-square analysis revealed that no significant difference of $\mathrm{ABO}$ and $\mathrm{Rh}$ subgroup distributions was evident between the patients with and without lung involvement $(\mathrm{p}=0.097$ and $\mathrm{p}=0.797$, respectively).

\begin{tabular}{|c|c|c|c|c|c|}
\hline & \multicolumn{4}{|c|}{ ABO blood subgroup } & \multirow{2}{*}{ Total } \\
\hline & A & B & $\mathrm{O}$ & AB & \\
\hline Patients without lung involvement & $21(36.8 \%)$ & $12(21 \%)$ & $23(40.4 \%)$ & $1(1.8 \%)$ & $57(100 \%)$ \\
\hline Patients with lung involvement & $80(51.9 \%)$ & $20(13 \%)$ & $46(29.9 \%)$ & $8(5.2 \%)$ & $154(100 \%)$ \\
\hline Total & 101 (47.9\%) & $32(15.2 \%)$ & 69 (32.7\%) & $9(4.2 \%)$ & $211(100 \%)$ \\
\hline
\end{tabular}

TABLE 3: Comparison of ABO subgroup distributions of the patients with and without lung involvement.

$\mathrm{p}=0.097$. 


\section{Cureus}

\begin{tabular}{|c|c|c|c|}
\hline & \multicolumn{2}{|c|}{ Rh blood subgroup } & \multirow{2}{*}{ Total } \\
\hline & Negative & Positive & \\
\hline Patients without lung involvement & $7(12.3 \%)$ & $50(87.7 \%)$ & $57(100 \%)$ \\
\hline Patients with lung involvement & $21(13.6 \%)$ & $133(86.4 \%)$ & $154(100 \%)$ \\
\hline Total & $28(13.3)$ & $183(86.7 \%)$ & $211(100 \%)$ \\
\hline
\end{tabular}

TABLE 4: Comparison of Rh subgroup distributions of the patients with and without lung involvement.

$\mathrm{p}=0.797$.

Table 5 presents the $\mathrm{ABO}$ subgroup distributions, and Table 6 presents the Rh subgroup distributions of patients both with PCR positivity and lung involvement, in comparison with the patients with only PCR positivity (without long involvement), and the patients with negative PCR test results. Chi-square analysis revealed that no significant difference of $\mathrm{ABO}$ and Rh subgroup distributions was evident among these three groups ( $\mathrm{p}=0.3$ and $\mathrm{p}=0.993$, respectively).

\begin{tabular}{|c|c|c|c|c|}
\hline \multirow[t]{2}{*}{ ABO blood subgroup } & \multicolumn{3}{|c|}{ PCR and lung involvement status } & \multirow{2}{*}{ Total } \\
\hline & PCR (-) & PCR+CT finding (-) & $\mathrm{PCR}+\mathrm{CT}$ finding (+) & \\
\hline A & 32 (47.8\%) & $17(36.2 \%)$ & $52(53.6 \%)$ & $101(47.9 \%)$ \\
\hline B & $12(17.9 \%)$ & $10(21.3 \%)$ & $10(10.3 \%)$ & $32(15.1 \%)$ \\
\hline $\mathrm{O}$ & $19(28.4 \%)$ & $19(40.4 \%)$ & $31(32 \%)$ & $69(32.7 \%)$ \\
\hline$A B$ & $4(5.9 \%)$ & $1(2.1 \%)$ & $4(4.1 \%)$ & $9(4.3 \% \%)$ \\
\hline Total & $67(100 \%)$ & $47(100 \%)$ & $97(100 \%)$ & 211 (100\%) \\
\hline
\end{tabular}

TABLE 5: Comparison of ABO subgroup distributions of three groups.

$\mathrm{p}=0.3$. PCR: polymerase chain reaction.

\begin{tabular}{|c|c|c|c|c|}
\hline \multirow[t]{2}{*}{ Rh blood subgroup } & \multicolumn{3}{|c|}{ PCR and lung involvement status } & \multirow{2}{*}{ Total } \\
\hline & PCR (-) & PCR+CT finding (-) & PCR+CT finding (+) & \\
\hline Negative & $9(13.4 \%)$ & $6(12.8 \%)$ & $13(13.4 \%)$ & 28 (13.3\%) \\
\hline Positive & 58 (86.6\%) & 41 (87.2\%) & $84(86.6 \%)$ & $183(86.7 \%)$ \\
\hline Total & $67(100 \%)$ & 47 (100\%) & 97 (100\%) & $211(100 \%)$ \\
\hline
\end{tabular}

TABLE 6: Comparison of Rh subgroup distributions of three groups.

$\mathrm{p}=0.993$. PCR: polymerase chain reaction.

\section{Discussion}

This study was conducted with a total of 211 patients with COVID-19, 144 of whom were confirmed with positive PCR test results obtained by specimens from nasal cavity and nasopharynx and the rest showed specific lung involvement on thorax computed tomography. According to our results there was no significant difference in $\mathrm{ABO}$ and $\mathrm{Rh}$ subgroup distributions between the patients with and without a positive PCR test result, and between the patients with and without lung involvement. Additionally, patients 
both with PCR positivity and lung involvement did not show a significantly different blood type distribution compared both to the patients with only PCR positivity (without lung involvement) and the patients with negative PCR test results.

AB0 blood group system antigens including A, B and $\mathrm{H}$ determinants are composed of complex carbohydrate molecules expressed on red blood cells and on many other cell surfaces/tissues such as epithelial cells, sensory neurons, platelets and endothelia of blood vessels [8]. Guillon et al. showed that human natural anti-A antibodies found in individuals with blood group $\mathrm{O}$ blocked the interaction between virus and its receptor, by inhibiting the adhesion of S spike protein of SARS-CoV-2 and interrupting the angiotensinconverting enzyme-2 expressing cell line [9]. According to this report, blood group AB that do not have antiA antibody might have a higher susceptibility to this infection like blood group A, but there does not exist any direct evidence in the literature to show that predisposition [10].

Many studies aiming to reveal the association between the $\mathrm{ABO}$ blood groups and various diseases revealed that $\mathrm{ABO}$ system might play an important role in the pathogenesis of immunological, cardiovascular, and neoplastic diseases $[11,12]$. ABO blood group system antibodies are a part of innate immune system and play role in the fight against some parasites, bacteria, and enveloped viruses [13,14]. In previous publications, certain blood group antigen expression was reported to alter host susceptibility to some infectious diseases. Association between $\mathrm{ABO}$ blood group antigens and specific pathogens such as Norwalk virus, dengue virus, hepatitis B virus and rotavirus was shown [4-7]. Furthermore, it was suggested that different prevalence of $\mathrm{ABO}$ blood group genotypes among various populations could be associated with selective pressure of some infectious diseases, particularly of the infections with Plasmodium falciparum and Vibrio cholera $[8,15]$.

Since the beginning of the SARS-CoV-2 pandemic, several studies have been conducted to investigate the relationship between blood groups and the risk and the frequency of infection. The first of these studies showed that blood group A was significantly higher in COVID-19 patients compared to the control group and blood group O in COVID-19 patients was significantly lower compared to the control group [16]. Similarly, Cheng et al. reported that those with blood group $\mathrm{O}$ had a lower frequency of SARS-CoV infection than the non-O groups during the SARS epidemic [17]. Afterwards, in studies conducted in various centers, it was shown that blood group A was associated with an increased risk of SARS-CoV-2 infection and blood group 0 had lower susceptibility to SARS-CoV-2 infection [18-20]. Zhao et al. also mentioned that blood group A was linked to higher mortality risk in discordance with blood group O [16].

Dzik et al. reported that percentage of individuals with blood group 0 was non-significantly and slightly higher in the population of Massachusetts and Boston. They explained this result by the Hispanic race dominancy of Boston, since blood group 0 was seen more frequently in Hispanics [21,22].

Goker et al. presented that blood group A was significantly more frequent and the blood group 0 was less frequent amongst 186 Turkish COVID-19 patients [20]. However, the present study demonstrates that ABO and Rh subgroup distributions are similar among the Turkish COVID-19 patients with and without a positive PCR test result and lung involvement. According to our results, there was no association of susceptibility to COVID-19 infection with ABO blood groups, among Turkish people. It may be considered that actual results in the literature might vary in different races and countries depending on the differences in blood group distribution. Thus, the blood group distribution of the patients with COVID-19 might be reflecting the distribution of the normal population. If the normal population has a specific blood group dominancy, patients with COVID-19 may have the same blood group dominancy as well.

The major limitation of this retrospective study was the small number of patients because the majority of patients diagnosed with COVID-19 did not have a recorded blood subgroup in their medical records, thus we included only the patients with a recorded blood subgroup.

\section{Conclusions}

In conclusion, people with all blood group types have an equal risk of COVID-19 infection. Everyone should follow the precautions to avoid the COVID-19 infection. However, underlying molecular mechanism of the relationship between the blood groups and the infection needs further molecular studies and larger multicenter research with individuals of different ethnicities. Revealing this linkage of $A B O$ and Rh system to the prevalence and mortality of COVID-19 is important in terms of understanding both the pathophysiology of the disease and the convalescent plasma therapy.

\section{Additional Information \\ Disclosures}

Human subjects: Consent was obtained or waived by all participants in this study. Local ethical committee of Giresun University issued approval 22.05.2020/17. This study was conducted in accordance with the dictates of World Health Organization- Declaration of Helsinki, after providing the official permission of Turkish Ministry of Health, Scientific Research Committee for COVID-19, with the informed consent of the patients and approval of the local ethical committee. Animal subjects: All authors have confirmed that this 
study did not involve animal subjects or tissue. Conflicts of interest: In compliance with the ICMJE uniform disclosure form, all authors declare the following: Payment/services info: All authors have declared that no financial support was received from any organization for the submitted work. Financial relationships: All authors have declared that they have no financial relationships at present or within the previous three years with any organizations that might have an interest in the submitted work. Other relationships: All authors have declared that there are no other relationships or activities that could appear to have influenced the submitted work.

\section{References}

1. Yin Y, Wunderink RG: MERS, SARS and other coronaviruses as causes of pneumonia . Respirology. 2018, 23:130-137. 10.1111/resp.13196

2. Zhou P, Yang XL, Wang XG, et al.: A pneumonia outbreak associated with a new coronavirus of probable bat origin. Nature. 2020, 579:270-273. 10.1038/s41586-020-2012-7

3. Zhou F, Yu T, Du R, et al.: Clinical course and risk factors for mortality of adult inpatients with COVID-19 in Wuhan, China: a retrospective cohort study. Lancet. 2020, 395:1054-1062. 10.1016/S01406736(20)30566-3

4. Tan M, Jin M, Xie H, Duan Z, Jiang X, Fang Z: Outbreak studies of a GII-3 and a GII-4 norovirus revealed an association between HBGA phenotypes and viral infection. J Med Virol. 2008, 80:1296-1301. $10.1002 / j m v .21200$

5. Kalayanarooj S, Gibbons RV, Vaughn D, et al.: Blood group AB is associated with increased risk for severe dengue disease in secondary infections. J Infect Dis. 2007, 195:1014-1017. 10.1086/512244

6. Kazi AM, Cortese MM, Yu Y, et al.: Secretor and salivary ABO blood group antigen status predict rotavirus vaccine take in Infants. J Infect Dis. 2017, 215:786-789. 10.1093/infdis/iix028

7. Liu J, Zhang S, Liu M, Wang Q, Shen H, Zhang Y: Distribution of ABO/Rh blood groups and their association with hepatitis B virus infection in 3.8 million Chinese adults: A population-based cross-sectional study. J Viral Hepat. 2018, 25:401-411. 10.1111/jvh.12829

8. Franchini M, Bonfanti C: Evolutionary aspects of ABO blood group in humans . Clin Chim Acta. 2015, 444:66-71. 10.1016/j.cca.2015.02.016

9. Guillon P, Clément M, Sébille V, Rivain JG, Chou CF, Ruvoën-Clouet N, Le Pendu J: Inhibition of the interaction between the SARS-CoV spike protein and its cellular receptor by anti-histo-blood group antibodies. Glycobiology. 2008, 18:1085-1093. 10.1093/glycob/cwn093

10. Zaidi FZ, Zaidi ARZ, Abdullah SM, Zaidi SZA: COVID-19 and the ABO blood group connection . Transfus Apher Sci. 2020, 59:102838. 10.1016/j.transci.2020.102838

11. Franchini M, Favaloro EJ, Targher G, Lippi G: ABO blood group, hypercoagulability, and cardiovascular and cancer risk. Crit Rev Clin Lab Sci. 2012, 49:137-149. 10.3109/10408363.2012.708647

12. Franchini M, Liumbruno GM: ABO blood group: old dogma, new perspectives. Clin Chem Lab Med. 2013, 51:1545-1553. 10.1515/cclm-2013-0168

13. Cooling L: Blood groups in infection and host susceptibility. Clin Microbiol Rev. 2015, 28:801-870. 10.1128/CMR.00109-14

14. Jing W, Zhao S, Liu J, Liu M: ABO blood groups and hepatitis B virus infection: a systematic review and meta-analysis. BMJ Open. 2020, 10:e034114. 10.1136/bmjopen-2019-034114

15. Glass RI, Holmgren J, Haley CE, et al.: Predisposition for cholera of individuals with O blood group. Possible evolutionary significance. Am J Epidemiol. 1985, 121:791-796. 10.1093/oxfordjournals.aje.a114050

16. Zhao J, Yang Y, Huang H, et al.: Relationship between the ABO Blood Group and the COVID-19 Susceptibility. Clin Infect Dis. 2020, 10.1093/cid/ciaa1150

17. Cheng $\mathrm{Y}$, Cheng $\mathrm{G}$, Chui $\mathrm{CH}$, et al.: $\mathrm{ABO}$ blood group and susceptibility to severe acute respiratory syndrome . JAMA. 2005, 293:1450-1451. 10.1001/jama.293.12.1450-c

18. Li J, Wang X, Chen J, Cai Y, Deng A, Yang M: Association between ABO blood groups and risk of SARS-CoV2 pneumonia. Br J Haematol. 2020, 190:24-27. 10.1111/bjh.16797

19. Abdollahi A, Mahmoudi-Aliabadi M, Mehrtash V, Jafarzadeh B, Salehi M: The novel coronavirus SARS-CoV2 vulnerability association with ABO/Rh blood types. Iran J Pathol. 2020, 15:156-160. 10.30699/ijp.2020.125135.2367

20. Göker H, Aladağ Karakulak E, Demiroğlu H, et al.: The effects of blood group types on the risk of COVID-19 infection and its clinical outcome. Turk J Med Sci. 2020, 50:679-683. 10.3906/sag-2005-395

21. Dzik S, Eliason K, Morris EB, Kaufman RM, North CM: COVID-19 and ABO blood groups. Transfusion. 2020, 60:1883-1884. 10.1111/trf.15946

22. Garratty G, Glynn SA, McEntire R: $A B O$ and Rh(D) phenotype frequencies of different racial/ethnic groups in the United States. Transfusion. 2004, 44:703-706. 10.1111/j.1537-2995.2004.03338.x 